\title{
An Approach to Digitalize the Health Care System of Bangladesh using Smartphone
}

\author{
Md. Kamrul Hossain ${ }^{1}$, Ahmed Imteaj ${ }^{2}$, Kazi Hassan Shakib ${ }^{3}$, Saika Zaman ${ }^{4}$ \\ ${ }^{1}$ Institute of Information and Communication Technology, \\ Chittagong University of Engineering and Technology, Bangladesh. \\ ${ }^{2}$ Knight Foundation School of Computing and Information Sciences, \\ Florida International University, Miami, FL 33199, USA. \\ ${ }^{3,4}$ Department of Computer Science and Engineering, \\ Chittagong University of Engineering and Technology, Bangladesh. \\ 1'muhammadkamrulhossain@gmail.com, ${ }^{2}$ aimteaj@gmail.com, ${ }^{3}$ kazishakib98@gmail.com, \\ ${ }^{4}$ saika_24@yahoo.com
}

Abstract - Health is one of the basic needs of human life. If this need cannot be fulfilled, then nothing can compensate for the loss. Often in Bangladesh, we observe that the economic ability of mass people can hardly ensure proper health care. The poor are being deprived of proper health care and even though the rich class can afford quality health care, but it comes with many compromises with their valuable time and labor. To meet the gap, we thought of a smartphone-based health care system that will assist people, especially the underprivileged, to attain health care easily and effectively. To effectively use the ICT facility that the government and nongovernment sectors are providing, we made a mobile application that will have several features including online appointment and cabin booking, prescription generator, hospital, and doctor's information displayed along with the suggestion, medicinal and disease information, etc. Since there is a great need for a system that can alarm people of emerging diseases in their area, we made a system to alarm people about that. Moreover, in the world of continuous changes, there is a great need for communication to acquire the latest knowledge. Hence a social network where doctors can discuss cures and medication will be of great benefit. Along with this, the need for continuous observation of medicinal side effects is not negligible. So, we need a proper channel for communication between patient and doctor, especially when a patient encounters some trouble when he takes the pre-scribed medications because of their side effects.

Keywords - Cabin booking; Healthcare; Interaction; Mo-bile Application; Social network.

\section{INTRODUCTION}

Nowadays, the smartphone has become one of the leading technologies that have opened a new sphere of innovation. This efficient tool can be used to serve humanity. With the development of information and communication technology (ICT), the internet is spreading rapidly across the country. At the same time, smartphones are reaching the hand of the masses at a great speed. As $3 \mathrm{G}$ internet service has been enabled all over the country, high-speed internet connection has made it possible to use cloud-based mobile and web applications. In the perspective of Bangladesh as a developing country, smartphone technology can play the most prominent role in materializing a friendly health care system that will reach the hand of the masses. Since most people are poor and not aware of proper health care, a smartphone-based health care system will benefit them immensely. To pro-vide them with necessary information about health, disease, cure, medication, hospital, doctors, etc. we made a mobile application. This 
application will provide the accurate and latest information in both Bengali and English language for better understanding. To help people in finding suitable hospitals this application will provide effective information such as facilities, location, number of doctors, specialization, number of cabins, cost of service, etc. This application will also provide the users with a comparative suggestion of hospitals in a city based on cost and/or quality of service. To help people book a cabin in a hospital in advance, this application provides a cabin booking system. Furthermore, this health care system also lets the user make an appointment with a doctor. It also has a database to store patients' vital information such as doctor's prescription, description of the disease, etc. This application will also serve as an assistant for the patients in an emergency as it has an emergency service calling facility, first aid information, etc. To help a patient in keeping track of his daily routine, this application provides some useful tools such as medication reminders, body mass index checking function, diet routine, etc. Then, we thought of a social networking platform for sharing diseaserelated experiences and in-formation. For example, a patient may ask his friends about a disease or problem, he is experiencing on that social platform and his friends will share with him their experiences regarding the problem. This will pave the way for effective health care. In the same way, the doctors will communicate with each other and share information about diseases and cures on that social platform. Then, we found that many organizations provide information about emerging diseases in various locations worldwide. We will collect this information about growing diseases in an area and alert the users of that area. This will aid in saving many lives because many a-times we see that people become victims for not getting prior alert of emerging diseases. Then, to help the patient get a prior idea about his illness or cure, there is a disease detection feature that gives a suggestion based on the users' input. For example, the application will show the user some questions and the user will give feedback according to his illness. After completing the process, the application will generate a suggestion based on its knowledge database. This feature will help the user to be aware of his health condition. Finally, we integrated into our application a platform for the patients and doctors to communicate. For example, after an appointment, the patient may come across some problems such as side effects from medication. So, with the help of the platform, the patient can interact with his doctor and discuss the problem. This feature will help the patients immensely because contacting a doctor and finding an appointment is not always easy. Sometimes it may take a month to get the appointment. So, in this way, this application will help to achieve a smart healthcare system by integrating a lot of useful functionalities on a common plat-form.

This paper is an extension of our previous work on a similar topic [1]. in [1], the authors deeply studied the then infrastructures of the medical sector of Bangladesh. They found that the lack of digitalization in the medical sector hindered desired growth of the sector. In this paper, we have discussed some relevant papers in section II. In section III we have chronicled the system functionality with technical details. Later we have shown a survey summary focusing on the necessity of our implemented healthcare system. Section V contains some challenges and future extensions of our work and finally, we conclude the paper.

\section{RELATED WORKS}

A few research studies are being conducted on the use of mobile technology to improve healthcare systems for people. This section presents the related studies on mobile phones as a tool for healthcare solutions. Arvie et. al. [2] proposed a mobile application named MedTouch, that helps to manage and access medical information and send them to nearby health care providers. 
Though their app makes healthcare easily accessible for the masses, it lacks in providing support for urgent or direct health care. A mobile application-based system was developed by authors in [3] that help doctors to manage and monitor their Alzheimer's patients. The application was specifically designed for Alzheimer's patients. More works need to be done to evaluate its usability among Alzheimer's patients and their caretakers. Authors in [4] described a personal health care system for diabetes patients. It uploads blood glucose information to a google sheet and this information can be used by doctors and health care providers for better treatment. Authors in [5] implemented a telehealthcare system for the people who are on diet. After collecting enough data from the user, the application can depict the progress of treatment. It can suggest to the patient what to do to gain proper weight. In [6], the authors suggested IoT base systems vulnerability and discussed a decision problem in taking an approach in making a solution into IoT based solutions. Authors in [7] wrote about a doctor recommender system that can suggest doctors to patients according to patients' needs. Though they evaluated their system comparing it with other similar systems, users' opinion about the application was not studied profoundly. In [8], the authors described a remote patient-monitoring and patient data retrieval system. There, in-formation was obtained using WAP protocol in a mobile phone. In [9] a smartphone-based application was demonstrated where the user can find useful information about the hospital. Though it has many features like staff and location finding, patient's medical records finding, etc. it cannot trace the user location in real-time. Authors in [10] propose an An-droid-based emergency medical system that works on the cloud. It can provide various useful information to the users, for example showing nearest hospital information. Authors in [11] developed a system of monitoring patients in the home and sending the collected data to software to identify whether any abnormality appears or not. Based on this it sends SMS to nearby doctors and caretakers. In [12], the authors developed an android application that has an emergency call function. But it does not include emergency SMS, email, etc. The authors in [13] discussed the train ticket booking system in China and they analyzed its performance. In this paper, we also have an online booking system for the cabin.

\section{METHOD}

This android application has several features, designed in a user-friendly way. The user can access each feature by clicking the appropriate button. The application has separate sections for the administrators and the users. It works both in online and offline mode. But data connection is necessary for updating. The complete system architecture and the logic diagram are depicted in Figure 1 and Figure 2, respectively.

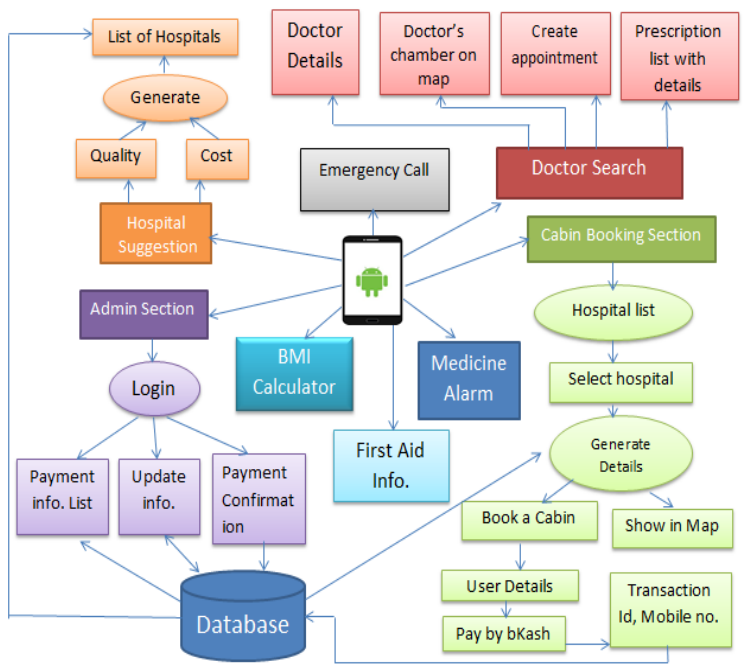

Figure 1. System Architecture 


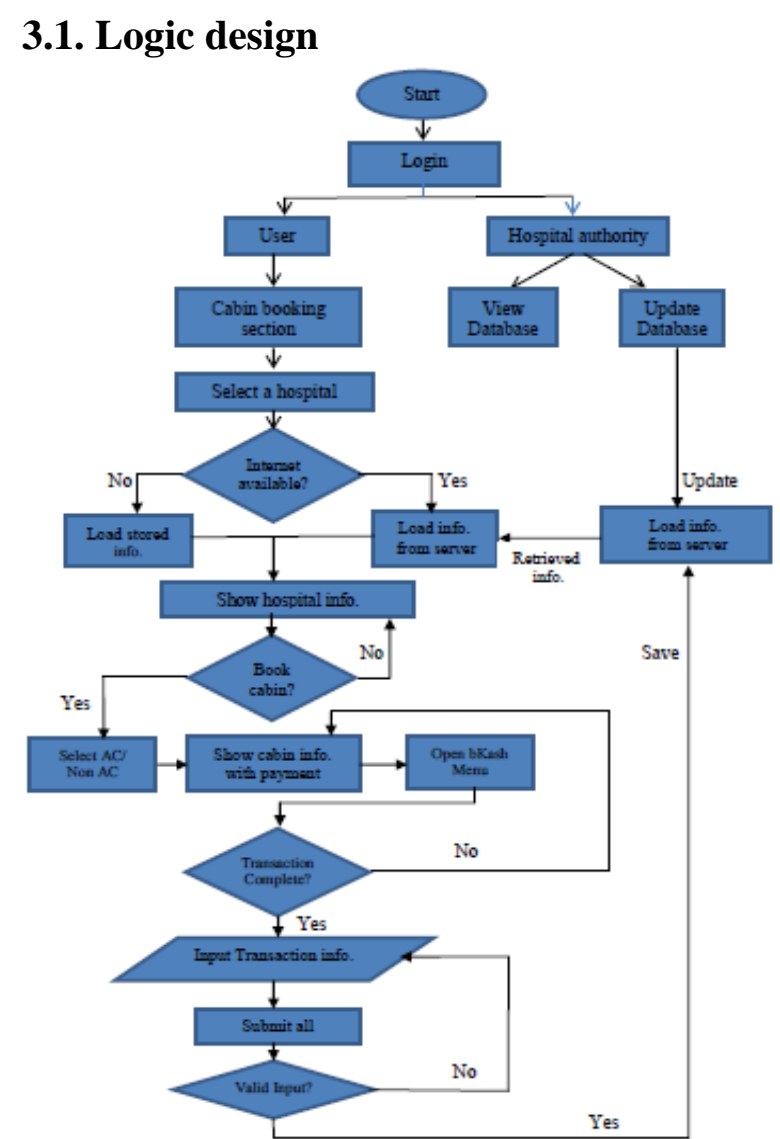

Figure 2. Logic diagram for booking a cabin

\subsection{Doctor-patient interaction}

The interaction between the patient and the doctor is of crucial importance. We know that many times the prescription of medication given by the doctor is followed by a sequence of appointments. The prescription changes by the course of the disease. Sometimes the prescribed medication result in unwanted side effects. Sometimes, the side effects on some patients are too harmful to ignore. So, therefore, continuous following up with the condition of the patient is vital. But that needs time and cost, which are not easy for many financially poor patients. In this circumstance, an application that makes the meeting between doctor and patient easier will be of vital importance and great benefits. In our application, we designed a section that will provide this feature. Both patient and doctor will have their profiles in the application database. After signing in, a doctor can find his patient and can follow up with him by knowing the ongoing effects of the medication. On the other hand, a patient can inform the about his present condition, side effects of the medication, etc. to the doctor. In this way, a new horizon will be opened where health care will be more fruitful and more effective. We depicted the doctorpatient interaction system in Figure 3.

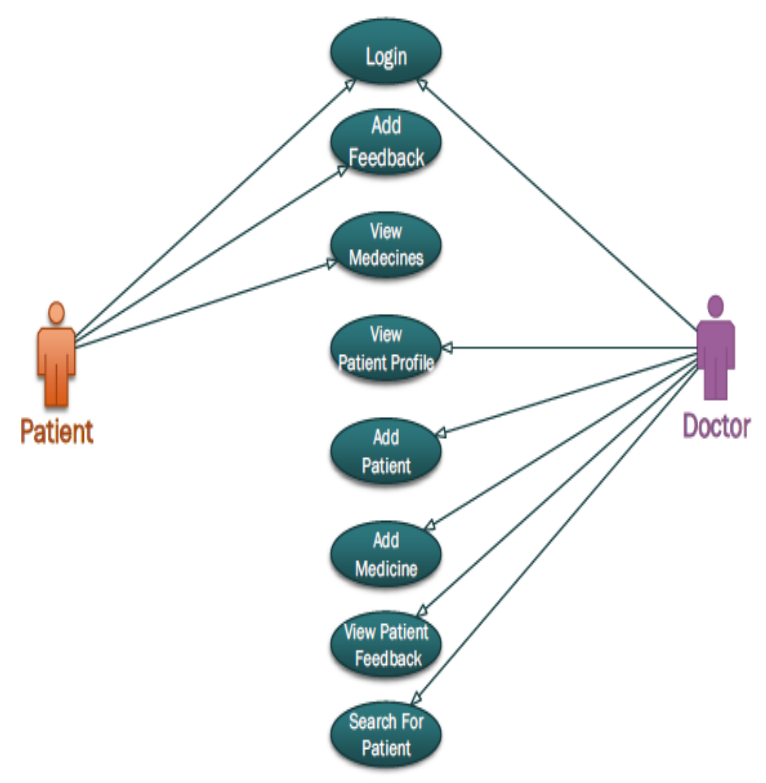

Figure 3. Use Case Diagram for Doctor-Patient Interaction

\subsection{Medication reminder}

The medicine alarm feature helps to set reminders about medicine to take. Through this feature, the user can set their medicine name, time to take the medicine, and alarm tone. The Android native SQLite database is used to save the alarm information. There are several methods used to activate the alarm. Android has the 'Alarm Manager' class. This class provides access to the system alarm services. These allow the system to schedule the application to be run at a particular time. After proper setting, the application will make an alarm with displaying the medicine name until the user dismiss it (Figure 4). 


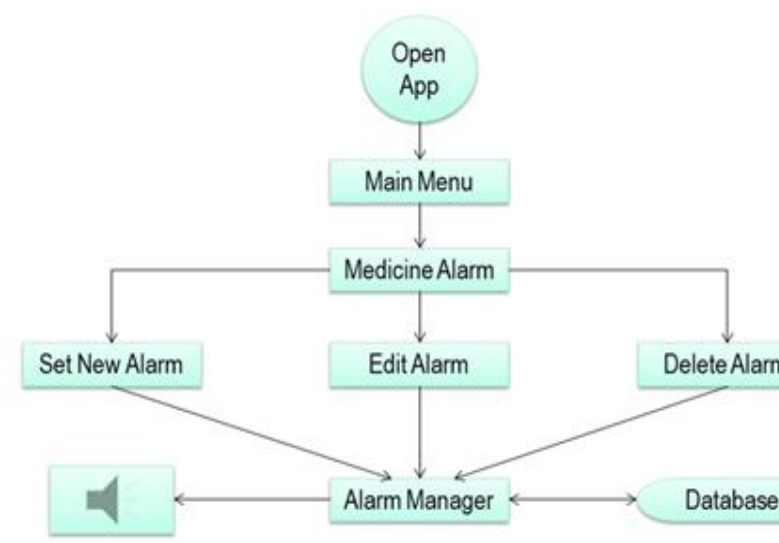

Figure 4. System diagram of medicine alarm

\subsection{A social network to share disease- related experiences and information}

We found that many times, people around us can help us by sharing their experiences regarding a disease. For example, suppose a person got a red mark on his body. Then he shows it to his friends and/or neighbor and discusses it. It is possible that one out of the people around him had such illness in the past and hence he can get suggestions from him on what to do next. Therefore, a social network where each person can share his ideas and experiences will benefit patients in several ways. For instance, many times, small illnesses do not need a certified doctor's consultancy. Rather, people who know about the illness can provide suggestions based on their experiences. Hence, the patient can save time and money because he can avoid consulting a doctor without any harm. Another important benefit is that a patient can get a suggestion about where to go or whom to consult for a particular disease. Besides, other benefits can emerge from such a social network. In the same way, we can think of a social network consisting of qualified doctors who will share and discuss ideas and information about medicine and diseases. For example, the doctor can discuss a new medicine's side effects. Furthermore, they can share their experiences about the treatment they provided and the feedback they received from a patient with a particular disease.

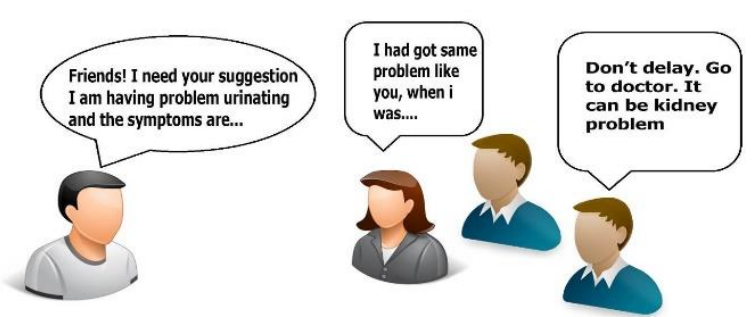

Figure 5. A patient asking about an illness in his community network

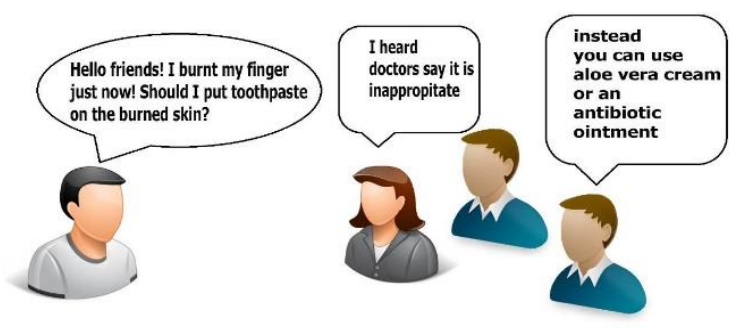

Figure 6. A patient asking about an illness in his community network

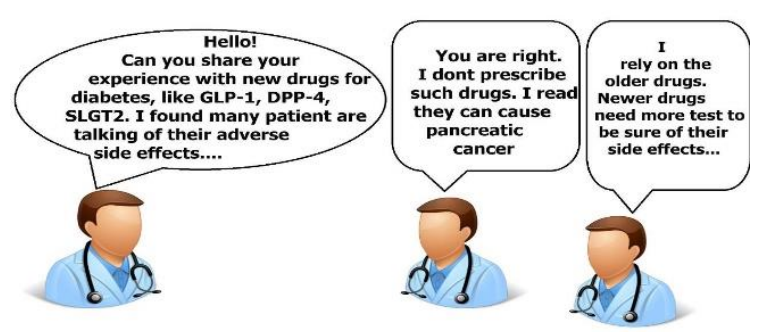

Figure 7. Doctors discussing some new drugs for type-2 diabetes in a community network

\subsection{Predicting uprising diseases by analyzing accumulated data}

A paper [14] published online in "The New England journal of medicine" showed that the day-to-day information found on the internet can be accumulated to find information about the latest uprising diseases worldwide. It can alert us of any upcoming epidemic disease so that we can take proper measures to protect ourselves. Besides, there are many organizations worldwide working on this and continue publishing the results on their websites. For example, 'healthmap.org' works with disease outbreak monitoring and continuous surveillance of developmental health threats [15]. So, therefore, we want to incorporate this feature into our application so that the users can easily get to know about the emerging diseases in their area and worldwide. The application will automatically alert the user of any potential 
epidemic disease in his area through a map (Figure 8).
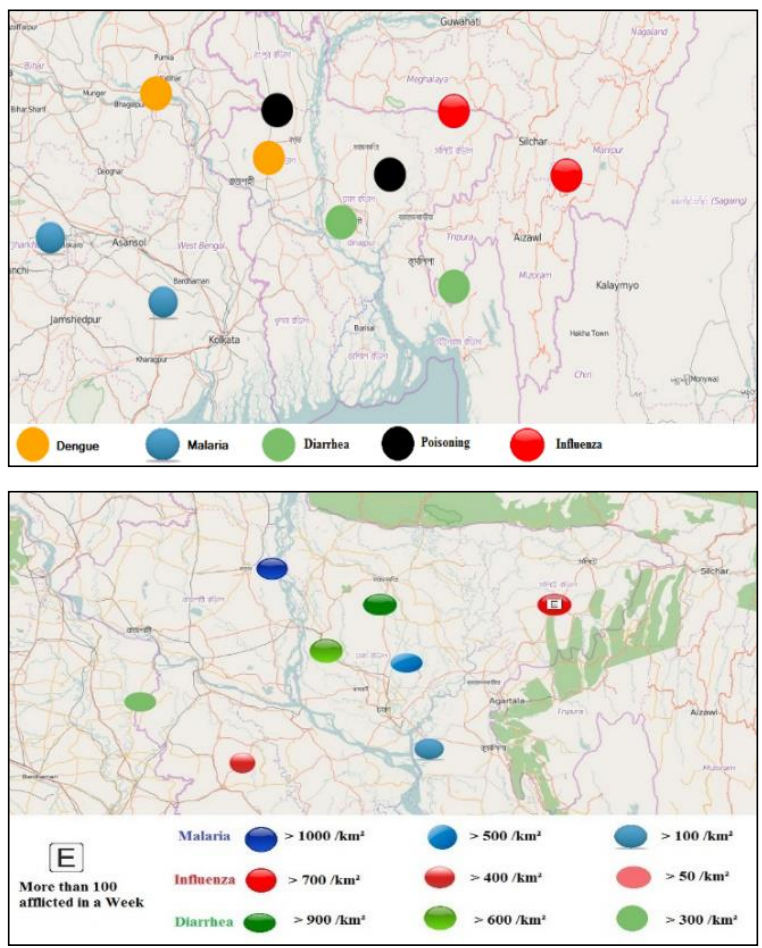

Figure 8. Health map showing diseases spreading in the regions

\subsection{Potential disease prediction}

Many online disease symptom checkers can do very well in finding the possible problem of human health. It is an easy and fast way to get primary information about the illness one is having. The program asks or lets the user choose from distinct options. Then step by step the program tries to find a cause for the problem the patient is facing. For example, 'www.webmd.com' provides a vivid and graphical way to find the possible cause of an illness [16]. First, it lets the user choose the body part of the illness (Figure 9). Then, it shows several more details of that part of the body to choose. This way the user gets a filtered list of elements. Lastly, the patient gets detailed information about the possible disease (Figure 10). This facilitates taking proper action and consultation with a proper doctor.
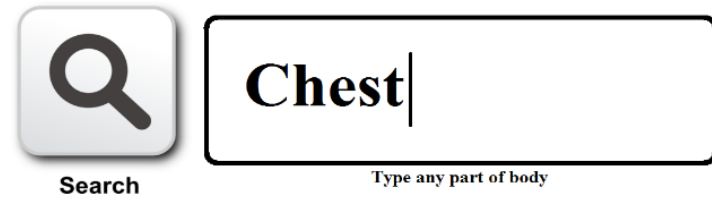

Figure 9. Search for a part of the body

\begin{tabular}{|l|l|}
\hline \multicolumn{1}{|c|}{ Chest Symptoms: } & \multicolumn{1}{c|}{$\begin{array}{c}\text { Possible Condition: } \\
\text { 1)Bleeding }\end{array}$} \\
2)Broken bone & $\begin{array}{l}\text { Your Choice: Pain } \\
\text { 3)Bruising }\end{array}$ \\
4)Cough & 1)Pleurisy \\
5)Difficulty breathing & 2)Costochondritis \\
6)Difficulty talking & 3)Pulmonary embolism \\
7)Getting stuck (swallowing) & 5)Pericarditis \\
8)Heartburn & 6)Muscle strain \\
9)Irregular heart rate & 7)Asthma \\
10)Pain & 8)Bronchial adenoma \\
& 9)Anxiety disorder \\
& 10)Peptic Ulcer \\
\hline
\end{tabular}

Figure 10. Detecting Possible Disease conditions based on user interactions

\section{RESULTS AND DISCUSSION}

\subsection{Experimental data}

For our research, we went to some renowned hospitals in Chittagong city and collected a large amount of data. Using these collected data and an algorithm described later, we generated a suggestive list of hospitals based on quality. It is a ranking of the hospitals based on the facilities provided by those hospitals. We have considered 5 attributes for calculating overall points obtained by a hospital. The data is given below in table 1 . For maintaining confidentiality, we did not mention the names of the hospitals we visited. Instead, we listed the hospitals with identifiers like hospital 1, hospital 2, etc.

Table 1. Measurement of quality

\begin{tabular}{|c|c|c|c|c|c|c|}
\hline $\begin{array}{c}\text { Nam } \\
\text { e of } \\
\text { Hosp } \\
\text { itals }\end{array}$ & $\begin{array}{l}\text { Total } \\
\text { cabin( } \\
\text { point) }\end{array}$ & $\begin{array}{c}\text { Total } \\
\text { non- } \\
\text { speciali } \\
\text { st } \\
\text { doctors( } \\
\text { point) }\end{array}$ & $\begin{array}{c}\text { Speciali } \\
\text { st } \\
\text { doctors( } \\
\text { point) }\end{array}$ & $\begin{array}{c}\text { Operati } \\
\text { on } \\
\text { Theater } \\
\text { (point) }\end{array}$ & $\begin{array}{c}\text { Ma } \\
\text { p } \\
\text { rati } \\
\text { ng } \\
\text { (poi } \\
\text { nt) }\end{array}$ & $\begin{array}{c}\text { Tot } \\
\text { al } \\
\text { poi } \\
\text { nts }\end{array}$ \\
\hline $\begin{array}{l}\text { Hosp } \\
\text { ital } 1\end{array}$ & $\begin{array}{l}100 \\
(10)\end{array}$ & $\begin{array}{c}58 \\
(5.8)\end{array}$ & $50(5)$ & $5(5)$ & 4 & $\begin{array}{c}29 . \\
8\end{array}$ \\
\hline $\begin{array}{l}\text { Hosp } \\
\text { ital } 2\end{array}$ & $\begin{array}{c}53 \\
(5.3)\end{array}$ & $\begin{array}{c}55 \\
(5.5)\end{array}$ & $57(5.7)$ & $4(4)$ & 3.7 & $\begin{array}{c}24 . \\
2\end{array}$ \\
\hline $\begin{array}{l}\text { Hosp } \\
\text { ital } 3\end{array}$ & $\begin{array}{l}130 \\
(10)\end{array}$ & $90(9)$ & $55(5.5)$ & $6(6)$ & 3.8 & $\begin{array}{c}34 . \\
3\end{array}$ \\
\hline $\begin{array}{l}\text { Hosp } \\
\text { ital } 4\end{array}$ & $90(9)$ & $50(5)$ & $40(4)$ & $5(5)$ & 3.8 & $\begin{array}{c}26 . \\
8\end{array}$ \\
\hline $\begin{array}{l}\text { Hosp } \\
\text { ital } 5\end{array}$ & $\begin{array}{c}75 \\
(7.5)\end{array}$ & $\begin{array}{l}144 \\
(10)\end{array}$ & $20(2)$ & $5(5)$ & 4.2 & $\begin{array}{c}28 . \\
7\end{array}$ \\
\hline $\begin{array}{l}\text { Hosp } \\
\text { ital } 6\end{array}$ & $\begin{array}{c}27 \\
(2.7)\end{array}$ & $\begin{array}{c}45 \\
(4.5)\end{array}$ & $\begin{array}{c}15 \\
(1.5)\end{array}$ & $3(3)$ & 3.0 & $\begin{array}{c}14 . \\
4\end{array}$ \\
\hline Hosp & $27(2.7)$ & 37 & 18 & $4(4)$ & 4.4 & 16. \\
\hline
\end{tabular}




\begin{tabular}{|c|c|c|c|c|c|c|}
\hline $\begin{array}{l}\text { Nam } \\
\text { e of } \\
\text { Hosp } \\
\text { itals }\end{array}$ & $\begin{array}{c}\text { Total } \\
\text { cabin( } \\
\text { point })\end{array}$ & $\begin{array}{c}\text { Total } \\
\text { non- } \\
\text { speciali } \\
\text { st } \\
\text { doctors( } \\
\text { point) }\end{array}$ & $\begin{array}{c}\text { Speciali } \\
\text { st } \\
\text { doctors( } \\
\text { point) }\end{array}$ & $\begin{array}{c}\text { Operati } \\
\text { on } \\
\text { Theater } \\
\text { (point) }\end{array}$ & $\begin{array}{c}\text { Ma } \\
\text { p } \\
\text { rati } \\
\text { ng } \\
\text { (poi } \\
\text { nt) }\end{array}$ & $\begin{array}{l}\text { Tot } \\
\text { al } \\
\text { poi } \\
\text { nts }\end{array}$ \\
\hline ital 7 & & (3.7) & (1.8) & & & 6 \\
\hline $\begin{array}{l}\text { Hosp } \\
\text { ital } 8\end{array}$ & $\begin{array}{c}38 \\
(3.8)\end{array}$ & $\begin{array}{c}35 \\
(3.5)\end{array}$ & $20(2)$ & $4(4)$ & 3.0 & $\begin{array}{c}16 . \\
3\end{array}$ \\
\hline $\begin{array}{l}\text { Hosp } \\
\text { ital } 9\end{array}$ & $\begin{array}{c}40 \\
(4.0)\end{array}$ & $\begin{array}{c}28 \\
(2.8)\end{array}$ & $\begin{array}{c}12 \\
(1.2)\end{array}$ & 4(4) & 3.5 & $\begin{array}{c}15 . \\
5\end{array}$ \\
\hline
\end{tabular}

We would like to state that, the ranking is subject to the values used for the attributes, and the values changes over time. This is because each hospital's facilities are upgraded from time to time. In the future, we would try to implement auto-update so that the table updates itself in real-time with the change of the data of the respective hospitals.

Now, we assigned points (between 1 to 10) for the values of attributes, except the attribute "map rating point". This rating point comes from Google Maps and its stores a public review about a place. People can give a place one to the five-star rating. We use this rating point (out of 5) as our "map rating point".

The point assigned to other attributes following the rule: If the value of an attribute is 100 or more, then we assign 10 points for that attribute for that hospital. Otherwise, we divide the value by 10 . The complete algorithm is given below:

The algorithm used for assigning points:

If No. of cabin, Doctor, specialist doctor $>=100$

Then point $=10$;

Else point $=$ No. of cabin, doctor, specialist doctor/ 10 ;

If $\mathrm{OT}>=10$ then point $(\mathrm{OT})=10$;

Else point $(\mathrm{OT})=\mathrm{OT}$;

Total point $=\{$ Point $($ Cabin $)+$ Point $($ No. of Doctor) + Point (Specialist Doctor) + Point (OT) + Map Rating Point\}

\subsection{Survey result}

The survey with a hundred users for the feedback of the application we built. There are three questions for each respondent. Those three questions are:
Question 1: Are these problems can be minimized by this application?

- Emergency but no available transport/cabin

- The hardship of finding the best suitable hospital

- Unawareness of appropriate doctor chamber

- Forgetfulness to take medication

Question 2: Did you like the online cabin booking and payment system?

Question 3: What is your opinion about the benefits and practicality of the application?

The list of questions and users' responses are accorded in table 2.

Table 2. Percentage of the responses to the questions

\begin{tabular}{|c|c|c|c|c|}
\hline $\begin{array}{l}\text { Respons } \\
\text { es to the } \\
\text { question }\end{array}$ & & Opt & & \\
\hline $\begin{array}{c}\text { Question } \\
1\end{array}$ & $\begin{array}{c}\text { Emergency } \\
\text { but no } \\
\text { available } \\
\text { transport/cab } \\
\text { in }\end{array}$ & $\begin{array}{c}\text { The } \\
\text { hardshi } \\
\text { p of } \\
\text { finding } \\
\text { the best } \\
\text { suitable } \\
\text { hospital }\end{array}$ & $\begin{array}{c}\text { Unawarene } \\
\text { ss of } \\
\text { appropriat } \\
\text { e doctor } \\
\text { chamber }\end{array}$ & $\begin{array}{c}\text { Forget } \\
\text { to take } \\
\text { medicin } \\
\text { e }\end{array}$ \\
\hline $\begin{array}{l}\text { Percentag } \\
\text { e of total }\end{array}$ & $70 \%$ & $10 \%$ & $5 \%$ & $15 \%$ \\
\hline $\begin{array}{c}\text { Question } \\
2\end{array}$ & Yes & No & Not sure & Maybe \\
\hline $\begin{array}{l}\text { Percentag } \\
\text { e of total }\end{array}$ & $80 \%$ & $3 \%$ & $10 \%$ & $7 \%$ \\
\hline $\begin{array}{c}\text { Question } \\
2\end{array}$ & $\begin{array}{l}\text { Practical and } \\
\text { beneficial }\end{array}$ & Useful & $\begin{array}{l}\text { Need further } \\
\text { developmen } \\
\text { t }\end{array}$ & $\begin{array}{c}\text { Cannot } \\
\text { say }\end{array}$ \\
\hline $\begin{array}{l}\text { Percentag } \\
\text { e of total }\end{array}$ & $65 \%$ & $15 \%$ & $10 \%$ & $10 \%$ \\
\hline
\end{tabular}

\section{CONCLUSION}

This application will open the door to thou-sands of possibilities to make the health care system more human-friendly. It gives easy access to vital information needed for every patient. In a third-world country like Bangladesh, where most people are poor, this application can show a new horizon in medical service. This application works with a cheap android phone, and it will always be 
free to use. Any user can use this application to easily book a cabin, to find hospital information, to know hospital located on the map, to get suggestions about hospital cost/quality, to get information about first aid and diet, to know BMI, to get emergency contacts, to set medicine reminder, etc. This application will help reduce the suffering patients undergo and it also can be a lifesaving friend.

\section{REFERENCES}

[1] A. Imteaj and M. K. Hossain, "A smartphone based application to improve the health care system of Bangladesh," 2016 International Conference on Medical Engineering, Health Informatics and Technology (MediTec), 2016, pp. 1-6, doi: 10.1109/MEDITEC.2016.7835358

[2] Carpio, Arvie, Jessub Kim, Rashina Hoda, and Duncan Miller. "Medtouch: Towards the development of smartphone based software solutions for mobile health care." In Proceedings of Australasian Software Engineering Conference, pp. 4-7. 2013.

[3] Habash, Zaid A., Wan Hussain, Wan Ishak, and Mohd Hasbullah Omar. "Android based application to assist doctor with Alzheimers patient." In International Conference on Computing and Informatics, vol. 28, pp. 511-516. 2013.

[4] Zhou, Fuchao, Hen-I. Yang, José M. Reyes Álamo, Johnny S. Wong, and Carl K. Chang. "Mobile personal health care system for patients with diabetes." In International Conference on Smart Homes and Health Telematics, pp. 94101. Springer, Berlin, Heidelberg, 2010.

[5] Chen, Han-Ping, Wei-Hsin Chen, Xing-Yu Su, Feipei Lai, Yi-Ju Chen, and Kuo-Chin Huang. "A web-based tele-healthcare system with mobile applica-tion and data analysis for diet people." In 2013 IEEE 15th
International Conference on e-Health Networking, Applica-tions and Services (Healthcom 2013), pp. 150-154. IEEE, 2013.

[6] Shakib, Kazi Hassan, and Farhin Faiza Neha. "A Study for taking an approach in Industrial IoT based Solution." In Journal of Physics: Conference Series, vol. 1831, no. 1, p. 012007. IOP Publish-ing, 2021.

[7] Jiang, Hongxun, and Wei Xu. "How to find your appropriate doctor: An integrated recommendation framework in big data context." In 2014 IEEE Sympo-sium on Computational Intelligence in Healthcare and e-health (CICARE), pp. 154-158. IEEE, 2014.

[8] Hung, Kevin, and Yuan-Ting Zhang. "Implementation of a WAP-based telemedicine system for patient monitoring." IEEE transactions on Information Tech-nology in Biomedicine 7, no. 2 (2003): 101-107.

[9] Luschi, Alessio, Andrea Belardinelli, L. Marzi, Francesco Frosini, Roberto Minia-ti, and Ernesto Iadanza. "Careggi Smart hospital: A mobile app for patients, citizens and healthcare staff." In IEEE-EMBS International Conference on Bio-medical and Health informatics (BHI), pp. 125-128. IEEE, 2014.

[10] Nimbalkar, Rashmi A., and R. A. Fadnavis. "Domain specific search of nearest hospital and Healthcare Management System." In 2014 Recent Advances in Engineering and Computational Sciences (RAECS), pp. 1-5. IEEE, 2014.

[11] Priya, B., S. Rajendran, R. Bala, and R. Gobbi. "Remote wireless health monitor-ing systems." In 2009 Innovative Tech-nologies in Intelligent Systems and Indus-trial Applications, pp. 383-388. IEEE, 2009.

[12] Sekar, Bhuvana, and Jiang B. Liu. "Location based mobile apps development on Android platform." In 2014 9th IEEE Conference on Industrial 
Electronics and Applications, pp. 21482153. IEEE, 2014.

[13] Song, Ci, and Weimin Wu. "Petri net modeling of information flow in the online train ticket booking system." In 2012 IEEE International Conference on Automation and Logistics, pp. 517522. IEEE, 2012.

[14] Brownstein, John S., Clark C. Freifeld, and Lawrence C. Madoff. "Digital disease detection-harnessing the Web for public health surveillance." The New England journal of medicine 360, no. 21 (2009): 2153.

[15] HealthMap- Global Health, Local Information, [http://www.healthmap.org/site/about]

[16] WebMD- Better Information, Better Health, [www.webmd.com] 